\title{
What Kind Of A Mobile Health App Do Patients Truly Want? A Pilot Study Among Ambulatory Surgery Patients
}

\author{
Meng-Yan Tang (D) \\ Zhi-Chao Li \\ Yan Dai \\ Xiao-Ling Li
}

Ambulatory Surgery Center, West China Hospital, Sichuan University, ChengDu, SiChuan 61004I, People's Republic of China
This article was published in the following Dove Press journal: Patient Preference and Adherence

Background: An increasing number of surgeries are performed as ambulatory surgeries, and mobile health applications (m-health apps) have therefore been designed to help provide patients with more convenient health-care services and improve the working efficiency of health-care professionals (HCPs). To find an effective approach to design such m-health apps, a study to evaluate ambulatory surgery patients' preferences is necessary.

Methods: A structured questionnaire was distributed to 360 patients undergoing ambulatory surgery to understand their demographic characteristics, preferences regarding the features and functions of m-health apps and willingness to engage with m-health apps.

Results: In total, $84.16 \%$ of ambulatory surgery patients stated that they would be willing to engage with an m-health app during the perioperative period. In addition, their top 10 necessary features and functions of $m$-health apps were related mainly to ambulatory surgery and communication with HCPs. Furthermore, younger age $\left(\chi^{2}=10.42, p<0.01\right)$, employment $\left(\chi^{2}=9.04, p<0.01\right)$, higher education $\left(\chi^{2}=13.67, p<0.01\right)$, longer daily use of phones $\left(\chi^{2}=11.84, p<0.01\right)$ and more frequent usage of m-health apps $\left(\chi^{2}=23.23, p<0.01\right)$ were associated with patients' willingness to engage with $\mathrm{m}$-health apps, but only more frequent usage of $\mathrm{m}$-health apps $(\mathrm{OR}=2.97,95 \% \mathrm{CI}=1.54-5.71, p<0.01)$ was found to be a predictor. Conclusion: This study presents an initial evaluation of ambulatory surgery patients' preferences regarding m-health apps. Gaining these insights will be useful to help us design an evidence-based, highly functional m-health app that best meets the needs of patients undergoing ambulatory surgery.

Keywords: mobile health applications, ambulatory surgery, preferences

\section{Introduction}

Currently, mobile health (m-health) is widely used in clinical practice; m-health is defined by the WHO as "medical and public health practice supported by mobile devices, such as mobile phones, patient monitoring devices, personal digital assistants and other wireless devices." ${ }^{1}$ In the context of increasing $4 \mathrm{G}$ network coverage and the popularization of smartphones, m-health was introduced to China in $2014^{2}$ Subsequently, China's m-health industry entered a rapid development stage, with a year-on-year growth rate of $29 \%$, and it surpassed a market size of $¥ 12.5$ billion (approximately US $\$ 1.90$ billion) in $2017^{3}$ this growth evidences its great potential and strong demand and suggests that $\mathrm{m}$-health will become a future trend in China's medical market. As the most popular technology in m-health, mobile health applications (m-health apps) refer to health-related smartphone application
School of Nursing, Sichuan University,

Guoxue Alley No.37, Wuhou District,

ChengDu, SiChuan 61004I, People's

Republic of China

Tel +86-I582823I2I5

Email janifer8I823@I63.com 
software for Android, iOS or other mobile terminal operating systems, with the characteristics of high informatization, high speed and high efficiency ${ }^{4}$ Previous studies have already shown that m-health apps have a positive impact on clinical practice by enhancing communication between patients and health-care professionals (HCPs) $)^{5}$ enhancing patients' self-management of disease ${ }^{6}$ reducing health-care costs $^{7}$ improving health care during the recovery period ${ }^{8}$ and providing patients with a feeling of not being alone. ${ }^{9}$

Ambulatory surgery is a type of surgery that allows patients to be admitted and discharged from the ambulatory surgery unit within $24 \mathrm{hrs} .{ }^{10}$ In 2014, Armstrong et al demonstrated that compared with in-person follow-up, m-health app follow-up was more cost-effective, with a cost difference of US $\$ 35$ per patient in the first postoperative month ${ }^{11}$ Later, in 2017, Armstrong et al carried out a randomized clinical trial study to prove that it is feasible to use m-health app follow-up in ambulatory surgery units, and the result showed that compared to inperson follow-up, m-health app follow-up affected neither complication rates nor patient-reported satisfaction scores but improved patient-reported convenience scores ${ }^{12}$ From 2015 to 2019, four studies further proved that the use of $\mathrm{m}$-health apps for monitoring the quality of recovery in postoperative ambulatory surgery patients at home was feasible and acceptable. ${ }^{9,13-15}$ HCPs have gradually realized that m-health apps could be an efficient, useful perioperative management tool, as some features and functions are highly valuable, such as reminders, online consultations with HCPs, review of test results, online postoperative follow-up and wound monitoring. ${ }^{15,16}$

The ambulatory surgery center of West China Hospital, Sichuan University, consists of three parts: an ambulatory surgery reservation center, an ambulatory surgery ward and an ambulatory surgery follow-up center. The ambulatory surgery center is equipped with 33 beds and has an annual surgery count of up to $6000-8000$. The three major ambulatory surgery types performed in the center are laparoscopic cholecystectomy (LC), mammotome minimally invasive (MMT) biopsy and resection of intestinal polyps (RIP). Since an increasing number of surgeries have been performed as ambulatory surgeries, the HCPs in our ambulatory surgery center have gradually become overworked ${ }^{17}$ Due to this situation, we would like to design an m-health app for ambulatory surgery centers to provide patients with more convenient health-care services and improve the working efficiency of HCPs. Before the m-health app can be systematically implemented, a comprehensive understanding of potential users and user habits is necessary ${ }^{18} \mathrm{M}$-health apps based on user-centered design have already been proven to be more practical and fully utilized than other m-health apps not designed with a usercentered approach; ${ }^{19,20}$ thus, surveys of patients' preferences regarding $m$-health apps can help effectively design m-health apps and enhance patients' engagement in m-health app interventions. Therefore, the aims of our study were to evaluate ambulatory surgery patients' preferences regarding $\mathrm{m}$-health apps, as well as their willingness to engage with m-health apps, and to identify specific patient variables associated with their willingness to engage with $\mathrm{m}$-health apps. Gaining this insight will help us identify an effective approach to design an evidence-based, highly functional $\mathrm{m}$-health app that best meets the needs of patients undergoing ambulatory surgery.

\section{Methods}

\section{Survey Development And Administration}

Based on a literature review and a rigorous brainstorming discussion (with physicians/nurses from the ambulatory surgery center and information technicians), the features and functions of the m-health app to be designed for our ambulatory surgery center were initially conceived and were divided into four subthemes: "My Ambulatory Surgery", "Online Consultation", "Postoperative Online Follow-up", and "Health Information". A total of 26 practical features and functions (as shown in Table 1) were identified. A structured questionnaire using a 4-point Likert scale was designed based on this initial concept for the app. The first part of the questionnaire included patients' demographic characteristics, including their age group, gender, occupational status, educational background, phone type, transportation time from home to the hospital, daily phone use, usage frequency of m-health apps, and ambulatory surgery type. In the second part of the questionnaire, items 1 to 26 were used to explore ambulatory surgery patients' preferences regarding m-health app features and functions. The responses were categorized as 1 - very unnecessary, 2 - unnecessary, 3 - necessary, and 4 - very necessary. Item 27 was used to assess ambulatory surgery patients' willingness to engage with $\mathrm{m}$-health apps. The responses were categorized as 1 - very unwilling, 2 unwilling, 3 - willing, and 4 - very willing.

Before the survey formally started, a presurvey of 100 ambulatory surgery patients was conducted to determine the reliability and validity of the questionnaire. The 
Table I Ambulatory Surgery Patients' Preference Regarding M-Health Apps

\begin{tabular}{|c|c|c|}
\hline Features And Functions & $\begin{array}{l}\text { Mean } \\
\text { Score } \pm \text { SD }\end{array}$ & Rank \\
\hline 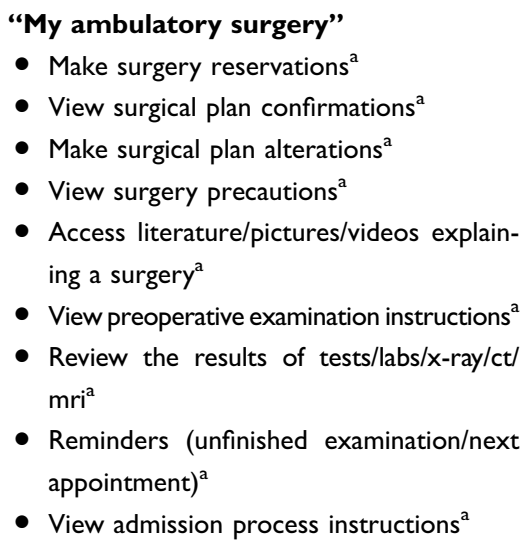 & $\begin{array}{l}3.27 \pm 0.67 \\
3.21 \pm 0.71 \\
3.13 \pm 0.81 \\
3.21 \pm 0.70 \\
3.07 \pm 0.73 \\
3.21 \pm 0.72 \\
3.23 \pm 0.72 \\
3.23 \pm 0.70 \\
3.22 \pm 0.68\end{array}$ & $\begin{array}{l}5 \\
3 \\
3 \\
4\end{array}$ \\
\hline $\begin{array}{l}\text { "Online consultation" } \\
\text { - Consult with hcps preoperative }{ }^{a} \\
\text { - Consult with hcps postoperative }{ }^{a} \\
\text { - Consultation fee demonstration }\end{array}$ & $\begin{array}{l}3.10 \pm 0.70 \\
3.19 \pm 0.69 \\
2.95 \pm 0.73\end{array}$ & $\begin{array}{l}8 \\
6 \\
15\end{array}$ \\
\hline $\begin{array}{l}\text { "Postoperative Online Follow-up" } \\
\text { - Postoperative follow-up through app } \\
\text { - Implement app follow-up on 2th day after } \\
\text { surgery } \\
\text { - Implement app follow-up on 3th day after } \\
\text { surgery } \\
\text { - Implement app follow-up on 7th day after } \\
\text { surgery } \\
\text { - Implement app follow-up on 28th day } \\
\text { after surgery } \\
\text { - Contact hcps for help through the app } \\
\text { when something wrong (wound disrup- } \\
\text { tionlbleedlinfection) }\end{array}$ & $\begin{array}{l}2.96 \pm 0.81 \\
2.83 \pm 0.85 \\
2.80 \pm 0.85 \\
2.79 \pm 0.86 \\
2.57 \pm 0.95 \\
3.36 \pm 0.75\end{array}$ & $\begin{array}{l}14 \\
17 \\
19 \\
20 \\
21 \\
1\end{array}$ \\
\hline $\begin{array}{l}\text { "Health information” } \\
\text { - View surgery complication information }{ }^{\mathrm{a}} \\
\text { - View wound care information }{ }^{\mathrm{a}} \\
\text { - View diet and nutrition information } \\
\text { - View medication information } \\
\text { - View discharge process instructions } \\
\text { - Information presented by literature and } \\
\text { - graphics }\end{array}$ & $\begin{array}{l}3.03 \pm 0.76 \\
3.10 \pm 0.75 \\
2.99 \pm 0.77 \\
3.01 \pm 0.77 \\
3.01 \pm 0.76 \\
3.05 \pm 0.75 \\
2.88 \pm 0.78 \\
2.8 I \pm 0.83\end{array}$ & $\begin{array}{l}10 \\
8 \\
13 \\
12 \\
12 \\
11 \\
16\end{array}$ \\
\hline
\end{tabular}

Note: ${ }^{a}$ Top 10 necessary features and functions of $m$-health app. Abbreviation: HCPs, health-care professions.

presurvey results showed that the questionnaire has good reliability and validity, with a Cronbach $\alpha$ coefficient of 0.95 and a content validity of 0.91 . The survey was officially administered in the ambulatory surgery ward of West China Hospital, Sichuan University, from June
2018 to December 2018. All questionnaires were distributed and collected by nurses between $3 \mathrm{pm}$ and $5 \mathrm{pm}$ on the day after surgery.

\section{Sampling}

The sample size was calculated according to the formula $N=4 U_{\alpha}^{2} S^{2} / \delta^{2}$, where $\alpha=0.05, \delta=0.1, S=0.67$ (results from the presurvey). The final sample size was set at 360 ambulatory surgery patients. The inclusion criteria were as follows: undergoing ambulatory surgery (LC/MMT biopsy/RIP), $>18$ years of age, and showing a normal level of cognition and communication skills. The exclusion criteria were as follows: visual impairment and an inability to read or complete the questionnaire. The structured questionnaire was distributed to a total of $380 \mathrm{ambu}-$ latory surgery patients, and 360 valid questionnaires were returned, with an effective rate of $94.7 \%$.

\section{Analysis}

The primary outcome of our study was the top 10 necessary features and functions of m-health apps. The second outcome was ambulatory surgery patients' willingness to engage with m-health apps. The third outcome was the specific patient variables associated with patients' willingness to engage with the app.

SPSS statistical software (version 22.0) was used to analyze the data. The top 10 necessary features and functions of m-health apps were described as the mean score \pm standard deviation (SD). The mean score \pm SD and percentage were used to describe ambulatory surgery patients' willingness to engage with m-health apps. In addition, the chi-squared test was employed in the univariate analysis to determine the significant variables associated with patients' willingness to engage with m-health apps. Subsequently, the significant variables were all included in a logistic regression model, and binary logistic regression was employed in the multivariate analysis. A $p$-value less than or equal to 0.05 was considered statistically significant.

\section{Ethical Consideration}

Ethical approval was obtained for this survey from the Ethics Committee of West China Hospital, Sichuan University. The questionnaires were completed anonymously after all participants provided informed consent. All the information involved in this study will remain confidential and will be used only for the aims of scientific research. 


\section{Results}

\section{Demographic Characteristics}

The mean age of the 360 ambulatory surgery patients was $40.81 \pm 16.13$ years old (ranging from 19 to 79 ). Among the patients, $160(44 \%)$ were male, and $200(56 \%)$ were female; $200(56 \%)$ were in the $<40$ age group, 115 (32\%) were in the 40-60 age group, and 45 (12\%) were in the $>60$ age group. A total of 239 patients $(66 \%)$ were employed, and 121 (34\%) were unemployed; 218 (61\%) had bachelor-level education or above, while 142 (39\%) had a high school-level education or below. In total, 341 (95\%) had smartphones and $19(5 \%)$ had non-smartphones; 180 (50) reported a transportation time from home to the hospital of less than $1 \mathrm{hr}, 96(27 \%)$ reported a time between 1 and $2 \mathrm{hrs}$, and $84(23 \%)$ reported a time of more than 2 hrs; and 254 (71\%) often used m-health apps, while 106 (29\%) had never used them ("Used in the past" is included in "often used", relevant explanations are available in the questionnaire so that patients can better understand). A total of 125 patients (35\%) were undergoing LC, 118 (33\%) were undergoing MMT biopsy and 117 (32\%) were undergoing RIP.

\section{First Outcome: Top 10 Necessary Features And Functions Of m-Health Apps}

The patients' preferences regarding $m$-health app features and functions are summarized in Table 1 . The 10 highest ranking items were as follows: No. 1 - contact HCPs for help through the app when something is wrong (3.36 $\pm 0.75)$; No. 2 - make surgery reservations (3.27 \pm 0.67$)$; No. 3 - review the results of tests/labs/X-ray/CT/MRI $(3.23 \pm 0.72)$ and reminders (3.23 \pm 0.70$)$; No. 4 - view admission process instructions (3.22 \pm 0.68 ); No. 5 - view surgical plan confirmations ( $3.21 \pm 0.71)$, surgery precautions $(3.21 \pm 0.70)$ and preoperative examination instructions (3.21 \pm 0.72$) ; \quad$ No. 6 - consult with HCPs postoperatively (3.19 \pm 0.69$)$; No. 7 - make surgical plan alterations $(3.13 \pm 0.81)$; No. 8 - consult with HCPs preoperatively (3.10 \pm 0.70$)$ and view wound care information (3.10 \pm 0.75$)$; No. 9 - access literature/pictures/videos explaining a surgery $(3.07 \pm 0.73)$; and No. 10 - view surgery complication information (3.03 \pm 0.76$)$.

\section{Second Outcome: Patients' Willingness To Engage With m-Health Apps}

The mean score for ambulatory surgery patients' willingness to engage with $\mathrm{m}$-health apps was $3.19 \pm 0.76$, and 303

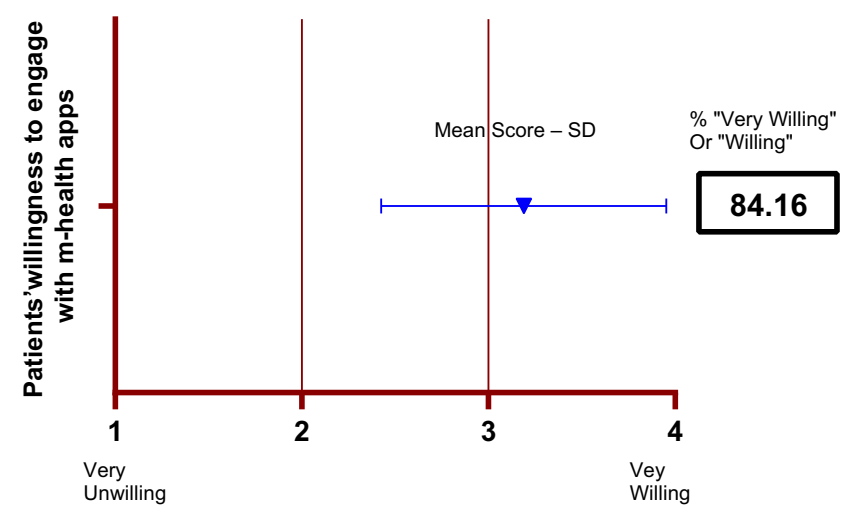

Figure I Patients willingness to engage with m-health apps.

(84.16\%) patients responded that they would be willing to engage with m-health apps during their perioperative period. The results are shown in Figure 1 (abscissa indicates the patient's willingness to engage with m-health apps, inverted triangle reflects mean score \pm standard deviation; percentage reflects proportion of respondents who responded, "very willing" or "willing".)

\section{Third Outcome: Variables Associated With Patients' Willingness To Engage With M-Health Apps}

The chi-squared test employed in the univariate analysis showed that younger age $\left(\chi^{2}=10.42, p<0.01\right)$, employment $\left(\chi^{2}=9.04, p<0.01\right)$, higher education $\left(\chi^{2}=13.67, p<0.01\right)$, longer daily use of phones $\left(\chi^{2}=11.84, p<0.01\right)$ and more frequent usage of m-health apps $\left(\chi^{2}=23.23, p<0.01\right)$ were associated with ambulatory surgery patients' willingness to engage with $\mathrm{m}$-health apps. The results are summarized in Table 2.

Furthermore, the binary logistic regression employed in the multivariate analysis showed that only more frequent usage of m-health apps was independently associated with ambulatory surgery patients' willingness to engage with $\mathrm{m}$-health apps $(\mathrm{OR}=2.97,95 \% \mathrm{CI}=1.54$ 5.71, $p<0.01)$. The results are summarized in Table 3.

\section{Discussion}

\section{Most Necessary Features And Functions}

Previous studies suggest that different kinds of patients have different preferences regarding m-health apps. Patients with chronic diseases are more inclined to desire features and functions such as reminders, health information and physiological/biochemical index trackers/monitors. For instance, patients with diabetes stated that the 
Table 2 Chi-Squared Test Employed In The Univariate Analysis

\begin{tabular}{|c|c|c|c|c|}
\hline Characteristic & $\begin{array}{l}\text { Not Willing } \\
(\mathrm{N}=57) \mathrm{n}(\%)\end{array}$ & $\begin{array}{l}\text { Willing } \\
(\mathrm{N}=303) \\
\mathrm{n}(\%)\end{array}$ & $\chi^{2}$ & $p$-Value \\
\hline $\begin{array}{l}\text { Age group, years } \\
\qquad 40 \\
40 \sim 60 \\
>60\end{array}$ & $\begin{array}{l}21(37) \\
24(42) \\
12(21)\end{array}$ & $\begin{array}{l}179(59) \\
91(30) \\
33(11)\end{array}$ & 10.42 & $<0.01$ \\
\hline $\begin{array}{l}\text { Gender } \\
\text { Male } \\
\text { Female }\end{array}$ & $\begin{array}{l}29(51) \\
28(49)\end{array}$ & $\begin{array}{l}|3|(43) \\
172(57)\end{array}$ & 1.13 & 0.31 \\
\hline $\begin{array}{l}\text { Occupational status } \\
\text { Employed } \\
\text { Unemployed }\end{array}$ & $\begin{array}{l}29(5 I) \\
28(49)\end{array}$ & $\begin{array}{l}211(70) \\
92(30)\end{array}$ & 9.04 & $<0.01$ \\
\hline $\begin{array}{l}\text { Educational } \\
\text { background } \\
\text { Bachelor and } \\
\text { above } \\
\text { High school and } \\
\text { below }\end{array}$ & $\begin{array}{l}22(38) \\
35(62)\end{array}$ & $\begin{array}{l}196(65) \\
107(35)\end{array}$ & 13.67 & $<0.01$ \\
\hline $\begin{array}{l}\text { Phone type } \\
\text { Smartphone } \\
\text { Non-Smartphone }\end{array}$ & $\begin{array}{l}6(11) \\
51(89)\end{array}$ & $\begin{array}{l}13(4) \\
290(96)\end{array}$ & 3.73 & 0.09 \\
\hline $\begin{array}{l}\text { Transportation time } \\
\text { from home to } \\
\text { hospital } \\
\quad<1 \mathrm{hr} \\
\quad 1 \sim 2 \mathrm{hr} \\
>2 \mathrm{hr}\end{array}$ & $\begin{array}{l}34(60) \\
13(23) \\
10(17)\end{array}$ & $\begin{array}{l}146(48) \\
83(27) \\
74(25)\end{array}$ & 2.61 & 0.27 \\
\hline $\begin{array}{l}\text { Daily phones use } \\
\qquad<\mathrm{hr} \\
1 \sim 2 \mathrm{hrs} \\
>2 \mathrm{hrs}\end{array}$ & $\begin{array}{l}11(19) \\
15(26) \\
31(55)\end{array}$ & $\begin{array}{l}19(6) \\
70(23) \\
214(71)\end{array}$ & 11.84 & $<0.01$ \\
\hline $\begin{array}{l}\text { Usage frequency of } \\
\text { m-health apps } \\
\text { Never use } \\
\text { Often use }\end{array}$ & $\begin{array}{l}32(56) \\
25(44)\end{array}$ & $\begin{array}{l}74(24) \\
229(76)\end{array}$ & 23.23 & $<0.01$ \\
\hline $\begin{array}{l}\text { Ambulatory } \\
\text { surgery type } \\
\text { LC } \\
\text { MMT biopsy } \\
\text { RIP }\end{array}$ & $\begin{array}{l}31(55) \\
9(15) \\
17(30)\end{array}$ & $\begin{array}{l}94(31) \\
109(36) \\
100(33)\end{array}$ & 5.51 & 0.06 \\
\hline
\end{tabular}

Abbreviations: LC, laparoscopic cholecystectomy; MMT biopsy, mammotome minimally invasive biopsy; RIP, resection of intestinal polyps.

most necessary features in m-health apps are medication reminders, blood glucose trackers and health information about diets and medication guidance ${ }^{21}$ while patients with psychological disorders preferred health information about exercise and sleeping ${ }^{22}$ For surgical patients, fewer studies
Table 3 Binary Logistic Regression Employed In The Multivariate Analysis

\begin{tabular}{|c|c|c|c|}
\hline \multirow[t]{2}{*}{ Characteristic } & \multicolumn{3}{|c|}{$\begin{array}{l}\text { Willingness To Engaging With } \\
\text { m-health App }\end{array}$} \\
\hline & $\begin{array}{l}\text { Unadjusted } \\
\text { OR }\end{array}$ & $95 \% \mathrm{Cl}$ & p-Value \\
\hline $\begin{array}{l}\text { Age group, years } \\
\qquad 40 \\
40 \sim 60 \\
>60\end{array}$ & $\begin{array}{l}\text { Ref } \\
0.57 \\
0.98\end{array}$ & $\begin{array}{l}- \\
(0.28,1.15) \\
(0.35,2.78)\end{array}$ & $\begin{array}{l}- \\
0.12 \\
0.98\end{array}$ \\
\hline $\begin{array}{l}\text { Occupational status } \\
\text { Unemployed } \\
\text { Employed }\end{array}$ & $\begin{array}{l}\text { Ref } \\
1.23\end{array}$ & $(0.56,2.74)$ & $\begin{array}{l}- \\
0.59\end{array}$ \\
\hline $\begin{array}{l}\text { Educational background } \\
\text { High school and below } \\
\text { Bachelor and above }\end{array}$ & $\begin{array}{l}\text { Ref } \\
1.65\end{array}$ & $\begin{array}{l}- \\
(0.80,3.43)\end{array}$ & $\begin{array}{l}- \\
0.17\end{array}$ \\
\hline $\begin{array}{l}\text { Daily phones use } \\
\qquad 1 \mathrm{hr} \\
1 \sim 2 \mathrm{hr} \\
>2 \mathrm{hr}\end{array}$ & $\begin{array}{l}\text { Ref } \\
1.99 \\
2.23\end{array}$ & $\begin{array}{l}- \\
(0.72,5.48) \\
(0.88,5.68)\end{array}$ & $\begin{array}{l}- \\
0.18 \\
0.09\end{array}$ \\
\hline $\begin{array}{l}\text { Usage frequency of } \\
\text { m-health apps } \\
\text { Never use } \\
\text { Often use }\end{array}$ & $\begin{array}{l}\text { Ref } \\
2.97\end{array}$ & $\begin{array}{l}- \\
(1.54,5.7 I)\end{array}$ & $<0.01$ \\
\hline
\end{tabular}

have investigated their preferences regarding m-health apps; to the best of our knowledge, only one study reported orthopedic patients' most desired features and functions for m-health apps. In Dattilo's study, the highest-ranking features were appointment reminders, viewable test results, communication with physicians and discharge instructions ${ }^{16}$ which is partly consistent with our results. In our study, the primary outcome showed that ambulatory surgery patients' top 10 necessary features and functions for m-health apps were related mainly to ambulatory surgery, such as No. 2-make surgery reservations, No. 3-review the results of tests/labs/X-ray/CT/MRI and reminders, No. 5-view surgical plan confirmations, surgery precautions and preoperative examination instructions, No. 7-view surgical plan alterations, No. 8-view wound care information, No. 9-access literature/pictures/ videos explaining a surgery, and No. 10-view surgical complication information. This result implies that our ambulatory patients were eager to find an easier way to go through the ambulatory surgical process; we believe this desire is related to the inconvenience of the current ambulatory surgical process in our hospital. In our 
ambulatory surgery center, when a patient is confirmed for an ambulatory surgery, they must complete all preoperative examinations on their own, as well as make the surgery reservation. Many patients have complained they had to travel between the outpatient clinics and the ambulatory surgery reservation center repeatedly, wasting a large amount of time and causing them substantial inconvenience. The results suggest we need to make our ambulatory surgical process easier and more convenient using $\mathrm{m}$-health apps. In addition, the results also show that the other most necessary features and functions of m-health apps were related to communication with HCPs, such as No. 1-contact HCPs for help through the app when something is wrong, No. 6-consult with HCPs postoperatively and No. 8-consult with HCPs preoperatively. This result is similar to that of Reddy, ${ }^{18}$ who reported that $88 \%$ of participants were most interested in m-health apps that would help them communicate with HCPs. This finding indicates that there may be a convenient approach to communication between ambulatory surgery patients and HCPs. Because an increasing number of surgeries are being performed as ambulatory surgeries, the HCPs in ambulatory surgery center have gradually become overworked $^{17}$ even though we established a special ambulatory surgery follow-up center in our hospital to address patients' needs after surgery (two nurses are in charge of follow-up-related affairs), which could still not meet all demands. In this case, communication with HCPs through m-health apps may be a compromise to solve this problem to some extent, as this function can fulfill patients' requirements of communicating with HCPs anytime and anywhere.

Recently, a systematic review concluded that the ideal m-health app for surgical patients should contain three stages of features and functions: at the preoperative stage, it should provide patients with preoperative education, surgery details, medication guidance and reminders; on the day of surgery, it should update patients regarding the approximate waiting times; and at the postoperative stage, it should provide patients with a symptom tracker, wound monitoring, online education and health information and follow-up ${ }^{5}$ However, most current m-health apps that are designed for ambulatory surgery patients are focused mainly on the postoperative stage and are typically used to monitor patients' recovery condition (wound and pain) and conduct online follow-up. ${ }^{9,12-15}$ In our study, we aimed to design an m-health app for use in our ambulatory surgery center with integrated features and functions. The primary outcome of this study therefore helps us determine what kind of m-health app ambulatory surgery patients truly want, and based on the results, we can infer which features and functions related to ambulatory surgery and communication with HCPs are most needed, which will provide us with practical guidance because we will assign more importance to these functions when developing the m-health app.

\section{Patients' Willingness To Engage With m-Health Apps And The Associated Variables}

To our surprise, we found that the majority of patients $(84.16 \%)$ were quite willing to engage with $\mathrm{m}$-health apps during their perioperative period. This result of our study shows a higher level of willingness compared with the results of other similar studies, ${ }^{18,23}$ indicating that there is a high demand for m-health apps in patients undergoing ambulatory surgery. Normally, m-health apps are fully utilized when patients have strong motivation ${ }^{24}$ which is the result we hope to see; however, the reality seems to be somewhat discouraging. One statistic shows that among the $165,000 \mathrm{~m}$-health apps that are available to patients, only $12 \%$ are downloaded and used, which indicates a current situation of poor usage ${ }^{25}$ The primary reason why patients stop using m-health apps is because the apps are unable to meet patients' demands for features and functions ${ }^{19}$ To promote patient engagement with m-health apps, the Food and Drug Administration in the United States has suggested the need for regulation of $\mathrm{m}$-health app content ${ }^{4}$ Meanwhile, some studies have proposed a user-centered model for m-health app design. ${ }^{19,20}$ Following this idea, we conducted this study to understand patients' preferences regarding $m$-health apps before designing and developing the app.

The results of our study showed that variables such as younger age, employment, higher education, longer daily use of phones and more frequent use of m-health apps were associated with patients' greater willingness to engage with m-health apps, but only more frequent use of $\mathrm{m}$-health apps was found to be the predictor.

Although many previous studies have already proven that younger age is associated with m-health app engagement, ${ }^{26,27}$ older people do not refuse to become involved with this new m-health technology. In contrast, Russell $^{28}$ found that older people had a positive attitude toward health-related apps, and Jonathan ${ }^{23}$ observed that 
older respondents showed the same willingness to engage with m-health apps as younger respondents. Regarding why older respondents showed a lower usage of m-health apps, a lack of confidence and unfamiliarity with apps were the most important reasons. In this case, to cater to both younger and older patients, simple interfaces and use instructions must be considered when designing the m-health app. Other similar studies have also shown that employment and higher education are associated with engagement with m-health apps. ${ }^{18,23}$ In Dattilo's study ${ }^{16}$ $40 \%$ of patients with higher income were more willing to pay for an app between US $\$ 1$ and US $\$ 5$, and more highly educated patients were more motivated to seek health resources and information through m-health apps. Moreover, our results indicated that more frequent m-health app use was a predictor of patients' willingness to engage with $\mathrm{m}$-health apps, which may be related to patients' trust in m-health apps. Patients will try to use m-health apps only when they trust them, and once they perceive the benefits through usage, they will continue to use them and help to promote them. Thus, to improve patients' trust in m-health apps, some strategies are necessary, such as reinforcing the firewalls of m-health apps to prevent the disclosure of patients' information and involving HCPs when promoting m-health apps ${ }^{22}$ Notably, variables that showed no significance provided us with some inspirations for how to design the m-health app. First, gender was not found to be significantly associated with patients' willingness to engage with $\mathrm{m}$-health apps in our study, which suggests that a neutral style may be more acceptable than a gendered style, for example, through the use of a neutral color such as green as the main color. In addition, the type of surgery was not found to be significant, which suggests that it is pointless to divide the content structure of $\mathrm{m}$-health apps according to the surgery type. Therefore, we decided to divide our m-health app into four subthemes according to the features and functions, such as "My Ambulatory Surgery", "Online Consultation", "Postoperative Online Follow-up", and "Health Information".

There are some limitations to this study. First, it is possible that the participants did not fully understand the questionnaire; therefore, we were reliant on the trained nurses to ensure adequate participant understanding, so there may have been interviewer-induced bias. Moreover, we conducted this study in only one ambulatory surgery center of one hospital, and only carried out surveys after surgery, which is not representative enough, suggesting that there may be selection bias; therefore, a multicenter survey in both pre-surgery and post-surgery could be carried out in the future. In addition, the readability of health education literature in this m-health apps was not covered in this study, relative study is recommended to be conducted in future.

\section{Conclusion}

This study presents an initial evaluation of ambulatory surgery patients' preferences regarding m-health apps. The results suggest that ambulatory surgery patients are very willing to engage with $\mathrm{m}$-health apps. They are eager to find an easier way to go through the ambulatory surgical process and wish to have a convenient approach to communicate with HCPs, so features and functions related to ambulatory surgery and communication with HCPs are most necessary. In addition, variables such as younger age, employment, higher education, longer daily use of phones and more frequent use of m-health apps are associated with patients' willingness to engage with such apps, which will help us identify an approach to better understand patients' preferences and needs regarding m-health apps. This information will be useful to both enlighten HCPs in ambulatory surgery centers and software developers/information technicians so they can successfully create m-health apps for patients undergoing ambulatory surgery.

\section{Acknowledgments}

This work was supported by the Youth Innovation Project Plan of Sichuan Medical Research [Q15048].

\section{Author Contributions}

Meng-Yan Tang and Zhi-Chao Li contributed equally as first authors. All authors contributed to data analysis, drafting or revising the article, gave final approval of the version to be published, and agree to be accountable for all aspects of the work.

\section{Disclosure}

The authors declare that they have no competing interests in this work.

\section{References}

1. M. Kay, J. Santos, M. Takane. mHealth: new horizons for health through mobile technologies. Global Observatory for Ehealth Series. Vol. 3. Geneva: World Health Organization; 2011. Available from: http://www.who.int/goe/publications/goe_mhealth_web.pdf. Accessed October 21, 2019 
2. Tian M, Zhang J, Luo R, et al. mHealth interventions for health system strengthening in China: a systematic review. JMIR Mhealth Uhealth. 2017;5(3):e32. doi:10.2196/mhealth.6889

3. Hsu J, Liu D, Yu YM, et al. The top Chinese mobile health apps: a systematic investigation. J Med Internet Res. 2016;18(8):e222. doi:10.2196/jmir.5955

4. Barton AJ. The regulation of mobile health applications. BMC Med. 2012;10(1):46. doi:10.1186/1741-7015-10-46

5. De La Cruz Monroy MFI, Mosahebi A. The use of smartphone applications (Apps) for enhancing communication with surgical patients: a systematic review of the literature. Surg Innov. 2019;26 (2):244-259. doi:10.1177/1553350618819517

6. Apolinario-Hagen J, Menzel M, Hennemann S, Salewski C. Acceptance of mobile health apps for disease management among people with multiple sclerosis: web-based survey study. JMIR Form Res. 2018;2(2):e11977. doi:10.2196/11977

7. Dahlberg K, Philipsson A, Hagberg L, et al. Cost-effectiveness of a systematic e-assessed follow-up of postoperative recovery after day surgery: a multicentre randomized trial. Br J Anaesth. 2017;119 (5):1039-1046. doi:10.1093/bja/aex332

8. Nussbaum R, Kelly C, Quinby E, Mac A, Parmanto B, Dicianno BE. Systematic review of mobile health applications in rehabilitation. Arch Phys Med Rehabil. 2019;100(1):115-127. doi:10.1016/j.apmr. 2018.07.439

9. Dahlberg K, Jaensson M, Nilsson U, Eriksson M, Odencrants S. holding it together-patients' perspectives on postoperative recovery when using an e-assessed follow-up: qualitative study. JMIR Mhealth Uhealth. 2018;6(5):e10387. doi:10.2196/10387

10. Ng L, Mercer-Jones M. Day case surgery guidelines. Surgery. 2014;32(2):73-78. doi:10.1016/j.mpsur.2013.12.006

11. Armstrong KA, Semple JL, Coyte PC. Replacing ambulatory surgical follow-up visits with mobile app home monitoring: modeling costeffective scenarios. J Med Internet Res. 2014;16(9):e213. doi:10.21 96/jmir.3528

12. Armstrong KA, Coyte PC, Brown M, Beber B, Semple JL. Effect of home monitoring via mobile app on the number of in-person visits following ambulatory surgery: a randomized clinical trial. JAMA Surg. 2017;152(7):622-627. doi:10.1001/jamasurg.2017.0111

13. Semple JL, Sharpe S, Murnaghan ML, Theodoropoulos J, Metcalfe KA. Using a mobile app for monitoring post-operative quality of recovery of patients at home: a feasibility study. JMIR Mhealth Uhealth. 2015;3(1):e18. doi:10.2196/mhealth.3929

14. Warren-Stomberg M, Jacobsson J, Brattwall M, Jildenstal P. At-home monitoring after surgery/anaesthesia - a challenge. J Eval Clin Pract. 2016;22(6):882-886. doi:10.1111/jep.12551

15. de Dicastillo EL, Garcia-Zapirain B, Fernandez MTA, de la Torre Diez I, Oleagordia I, Celaya AA. Development and evaluation of a telematics platform for monitoring of patients in ambulatory major surgery. Telemed J E Health. 2019;25(2):152-159. doi:10.1089/ tmj.2017.0296
16. Datillo JR, Gittings DJ, Sloan M, Hardaker WM, Deasey MJ, Sheth NP. "Is there an app for that?" Orthopaedic patient preferences for a smartphone application. Appl Clin Inform. 2017;8(3):832-844. doi:10. 4338/ACI-2017-04-RA-0058

17. Herrera-Usagre M, Santana V, Burgos-Pol R, et al. Effect of a mobile app on preoperative patient preparation for major ambulatory surgery: protocol for a randomized controlled trial. JMIR Res Protoc. 2019;8(1):e10938. doi:10.2196/10938

18. Reddy R, Majmudar M, Dhopeshwarkar N, Vacaro V, Isselbacher E, Bhatt AB. Mobile health apps preferences and practice among ambulatory cardiovascular patients. Future Cardiol. 2018;14(5):381-388. doi:10.2217/fca-2018-0005

19. Schnall R, Rojas M, Bakken S, et al. A user-centered model for designing consumer mobile health (mHealth) applications (apps). $J$ Biomed Inform. 2016;60:243-251. doi:10.1016/j.jbi.2016.02.002

20. Mccurdie T, Taneva S, Casselman M, et al. mHealth consumer apps: the case for user-centered design. Biomed Instrum Technol. 2012;46 (s2):49-56. doi:10.2345/0899-8205-46.s2.49

21. Adu MD, Malabu UH, Malau-Aduli AEO, Malau-Aduli BS. Users' preferences and design recommendations to promote engagements with mobile apps for diabetes self-management: multi-national perspectives. PLoS One. 2018;13(12):e0208942. doi:10.1371/journal. pone.0208942

22. Lipschitz J, Miller CJ, Hogan TP, et al. Adoption of mobile apps for depression and anxiety: cross-sectional survey study on patient interest and barriers to engagement. JMIR Ment Health. 2019;6(1): e11334. doi: $10.2196 / 11334$

23. Abelson JS, Symer M, Peters A, Charlson M, Yeo H. Mobile health apps and recovery after surgery: what are patients willing to do? Am J Surg. 2017;214(4):616-622. doi:10.1016/j.amjsurg.2017.06.009

24. Raval MV, Taylor N, Piper K, et al. Pediatric patient and caregiver preferences in the development of a mobile health application for management of surgical colorectal conditions. J Med Syst. 2017;41 (7):105. doi:10.1007/s10916-017-0750-3

25. Teo $\mathrm{CH}, \mathrm{Ng} \mathrm{CJ}$, White A. What do men want from a health screening mobile app? A qualitative study. PLoS One. 2017;12(1):e0169435. doi:10.1371/journal.pone.0169435

26. Kontos E, Blake KD, Chou WY, Prestin A. Predictors of eHealth usage: insights on the digital divide from the Health Information National Trends Survey 2012. J Med Internet Res. 2014;16(7):e172. doi:10.1371/journal.pone.0169435

27. Asan O, Cooper IF, Nagavally S, et al. Preferences for health information technologies among US adults: analysis of the Health Information National Trends Survey. J Med Internet Res. 2018;20 (10):e277. doi:10.2196/jmir.9436

28. Russell AM, Smith SG, Bailey SC, et al. Older adult preferences of mobile application functionality supporting medication self-management. J Health Commun. 2018;23(12):1064-1071. doi:10.1080/1081 0730.2018 .1554728
Patient Preference and Adherence

\section{Publish your work in this journal}

Patient Preference and Adherence is an international, peer-reviewed, open access journal that focusing on the growing importance of patient preference and adherence throughout the therapeutic continuum. Patient satisfaction, acceptability, quality of life, compliance, persistence and their role in developing new therapeutic modalities and compounds to optimize clinical outcomes for existing disease states are major areas of interest for the journal. This journal has been accepted for indexing on PubMed Central. The manuscript management system is completely online and includes a very quick and fair peer-review system, which is all easy to use. Visit http:// www.dovepress.com/testimonials.php to read real quotes from published authors. 